ECONOMICS

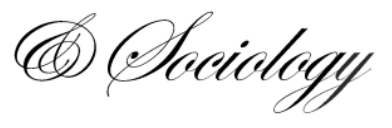

Pratomo, D. S. (2018). Can Rural-Urban Migrants Escape from Poverty? Evidence from Four Indonesian Cities. Economics and Sociology, 11(2), 173-183. doi:10.14254/2071-789X.2018/11-2/12

\title{
CAN RURAL-URBAN MIGRANTS ESCAPE FROM POVERTY? EVIDENCE FROM FOUR INDONESIAN CITIES
}

\author{
Devanto Shasta Pratomo, \\ Brawijaya University, \\ Malang, Indonesia, \\ E-mail:dede_gsu02@yahoo.com
}

Received: December, 2017 1st Revision: March, 2018 Accepted: May, 2018

DOI: $10.14254 / 2071-$ 789X.2018/11-2/12

\begin{abstract}
This study examines the probability of rural-urban migrants in Indonesia living under poverty at destination. The poverty levels is divided into three categories including poor households, near-poor households, and non-poor households, basing on the definition of Indonesian Central Bureau of Statistics's poverty lines using the expenditure approach. Using Rural-Urban Migration of Indonesia and China (RUMiCI) 2011 data, the findings show that migrants tend to be categorized as non-poor as compared to non-migrants. The important factors that help migrants to escape from poverty include education of household heads, the number of dependents, and previous working experience in the modern sectors.
\end{abstract}

JEL Classification: 132, J61, Keywords: poverty; migration; rural-urban migrants. R23

\section{Introduction}

The movement of population from rural to urban areas (rural-urban migration) plays an important role in social and economic development in many countries, including Indonesia (Skeldon, 2002; Tacoli et al., 2008). In Indonesia, approximately three million people had migrated in the last five years from villages to towns or cities (Manning and Pratomo, 2013). Meng and Manning (2010) also noted that $15 \%$ of the total urban population in Indonesia are migrants and were born outside their present place of residence. The recent rural-urban migration in Indonesia has mainly been driven by the development in industry and services sectors located in the largest cities of the country (Firman et al., 2007). Urban areas typically have an environment with more prospects for employment and provides greater options for the relevant today employment instead of being limited to less productive agricultural jobs typical for rural areas.

Although labor force participation among migrants is high, some migrants, especially those who are new to cities, experience difficulties with getting jobs in advancely developed economic sector (Manning and Pratomo, 2013). Many migrants, therefore, become involved in the urban informal sector with its unsatisfactory living conditions, less stable occupation and earnings. Effendi et al. (2009) stated that around 80\% of new migrants in Indonesia are working in the unskilled occupations' sector. This is because of their lower educational attainment, lesser adaptation to urban environment, and lesser involvement in social networking as compared to local residents.

This condition has important implications for the welfare of migrants relative to their destination. Park and Wang (2010) showed that in China, the hourly earnings of migrants are much lower (around one third) as compared to those of local residents, implying higher 
probability of the migrants being poor. High participation of migrant labor force at destination is also not a guarantee that migrants will not be poor (Skeldon, 2002; Odhiambo and Manda, 2003). Gong et al. (2012) indicated that 21 percent of rural-urban migrants in China are trapped in urban poverty. Using data in several low- and middle-income countries, Tacoli et al. (2008) also showed that the proportion of migrants among the urban poor ranges from 7 percent in Nigeria (the lowest), to 43 percent in Bolivia (the highest). Meanwhile, Resosudarmo et al. (2009a) found that more than 10 percent of the lifetime migrants in Indonesia are likely to be among poor households. Due to poverty conditions, many poor migrants in Indonesia are also found to be sources of urban problems, such as the proliferation of slum areas in many big cities (Effendi et al., 2009).

However, the relationship between poverty and rural-urban migration is far from conclusive. In the case of China, Park and Wang (2010) showed that the impact of migration on urban poverty is not significant. Although hourly earnings of migrants are lower than those of local residents, migrants tend to work more hours compared to local residents. They also tend to have lower dependency ratio due to dominance of young and single person migrants, reducing the likelihood of poverty as measured based on their per capita expenditures. In Indonesia, many migrants also survived by leaving their families behind in home villages (Effendi et al., 2009). This implies that the living costs of migrant households in cities may be lower than that of local residents.

Using Indonesian dataset, Resosudarmo et al. (2009a) found that migrant households are less likely to be poor than nonmigrants living in a same city. This suggests that migrants, particularly recent ones, in fact, have better socioeconomic status than local residents. This is also in line with the finding of (Skeldon, 2002) who showed that rural-urban migrants are more likely to be not the poorest group in their village. Park and Wang (2010) also indicated that in China, rural-urban migrants tend to have better human capital than those who remain behind in rural areas.

Based on these findings, this study determines the probability that rural-urban migrants in Indonesia live in poverty at their destination points (that is, in cities). To obtain specific results, the poverty level is divided into three categories: (i) migrants living in poor households, (ii) migrants living in near-poor households, and (iii) migrants living in non-poor households. The near-poor households category is added to see the vulnerable groups between the poor and the non-poor categories. These categories are examined based on the definition of poverty line by the Indonesian Central Bureau of Statistics. The definition of poverty line, which uses the expenditure approach, covers each specific district.

Using the migrants only data, this study is then extended by analyzing the dynamics of the migrant socioeconomic conditions in the villages (origin) and in the cities (destination). The previous condition in the place of origin includes whether the would-be migrants had nonagricultural (modern sector) experiences and how much they were earning before they moved to the cities. This study predicts that migrants with nonagricultural experiences at place of origin will benefit in terms of adaptation with the modern sector employment, thus, decreasing the likelihood of being paid lower and being poor. Meanwhile, the estimated earnings in the village are a proxy of migrants' financial background at place of origin. This financial background could lower the probability of being poor at destination. The migration status will also be specifically compared between lifetime migrants and recent migrants based on their duration of stay in the city.

Despite the importance of this study for policy development, developing countries usually suffer from a scarcity of data particularly on rural-urban migration. This study takes advantage of the longitudinal data source of Rural-Urban Migration of Indonesia and China (RUMiCI) conducted by the Australian National University (ANU) to investigate the labor market activities and socioeconomic conditions of individuals who have migrated from rural 
to urban areas. In practice, RUMiCI covers four largest rural-urban migration destination representing four big islands in Indonesia, including Tangerang as suburban area of Jakarta (Java), Medan (Sumatera), Samarinda (Kalimantan), and Makassar (Sulawesi).

This paper is outlined as follows: Section 2 reviews the literature used as background of the study, Section 3 describes the methodology and sample covered in the RUMiCI survey in the four cities of Indonesia, while Section 4 discusses the empirical results of the study. The final section summarizes the findings and conclusions.

\section{Literature Review}

There have been less studies done on the effects of rural-urban migration on poverty in developing countries. Many studies have focused on the effects of international migration on poverty, particularly migration from developing countries to developed countries (see for example Galloway and Aaberge (2005 and Lelkes (2007). Using the data of European Union (EU) countries, Lelkes (2007) found that migrants who are not citizens of their country of residence tend to have higher risk of poverty at destination because of higher difficulties in adapting to the new environment. Specifically, Lelkes (2007) noted that non-EU migrants tend to have twice as high a risk of poverty at destination than EU migrants that have similar background with local residents (nonmigrants). However, as pointed out by Galloway and Aaberge (2005), in the case of Norway, immigrants with longer duration of stay reduced the probability of being poor at destination due to the fact that their labor force participation and performance increased over time in line with their assimilation.

The other studies examined the effects of migration and its remittances on poverty at the origin in the case of developing countries (see for example Yang and Martinez 2005 and Adams Jr. and Page 2005). Using cross-country data, Adams Jr and Page (2005) found that international migration and remittances reduce poverty in developing countries. Specifically, they found that a 10 percent increase in the share of international migrants in the country's population reduced poverty as measured by the share of people living below $\$ 1$ per day by 2.1 percent. Yang and Martinez (2005) found that remittance flow by Filipino international migrants decreased the poverty at home during the 1997 Asian financial crisis, supported by the appreciation of currency at destination against the Philippine peso. Comparing international and internal remittances, Adams $\mathrm{Jr}$ et al. (2008) showed that international remittances have a greater impact in reducing poverty than internal remittances in Ghana. Meanwhile, in Indonesia, Adams $\mathrm{Jr}$ and Cuecuecha (2010) found that international remittances have also a significant impact in reducing poverty. However, migrants tend to spend on consumption rather than on investment goods, suggesting the potential short-term impact only on poverty.

Using China Urban Labor Survey in 10 cities, Park and Wang (2010) examined the effects of migration on urban poverty and inequality. Interestingly, the studies found no significant differences in the poverty level of migrants to that of local residents. Although migrants have lower hourly earnings than local residents, they worked longer hours, have higher labor force participation rate, and have lower dependency ratio, reducing the probability of being categorized as poor households as measured by per capita household expenditure. The result is in contrast with the study by Odhiambo and Manda (2003) using Welfare Monitoring Survey in Kenya, showing that the higher labor force participation rate does not guarantee that urban households can escape poverty. This is mainly due to the fact that the working poor in Kenya are mostly employed in low-productivity industries, including the informal sectors. Moreover, although rural-urban migrants, in the case of China, tend to be not categorized as poor households, Park and Wang (2010) pointed out that migrants still face 
difficulties in accessing non-income welfare in the cities, including housing and social insurance programs.

Using the same dataset of Indonesia, Resosudarmo et al. (2009a) found that the average household income of migrants is significantly higher than that of local residents. They are also less likely to be poor than the nonmigrants as measured by improvements in their socioeconomic status. The age of household head upon leaving the village is significant in influencing the poverty status of a migrant, suggesting that younger age at migration has lower probability of being poor. Using data from developing countries on socioeconomic status, Tacoli et al. (2008) suggest that rural-urban migrants are usually better educated than those who stay behind in the village. They are also better off in terms of economic resources, which serve as an economic advantage over the poorest urban groups. In the case of a developed country, Weber et al. (2007) found that migration status does not significantly influence poverty at destination because the rural population in a developed country (e.g., US) tends to be relatively wealthy. However, they also indicate that socioeconomic status - such as education, gender, and family size - are important in determining poverty at destination.

The introduction should briefly place the study in a broad context and highlight why it is important. It should define the purpose of the work and its significance. The current state of the research field should be reviewed carefully and key publications cited. Please highlight controversial and diverging hypotheses when necessary. Finally, briefly mention the main aim of the work and highlight the principal conclusions.

\section{Data and Methodology}

The main dataset used for this study is the 2011 Rural-Urban Migration in China and Indonesia (RUMiCI), focusing on Indonesia, as surveyed by the Australian National University. RUMiCI is a longitudinal household-level survey conducted during 2008-2011 to investigate the labor market activities and socioeconomic conditions of individuals who have migrated from rural to urban areas and who were living in the four largest recent migrant destination cities in Indonesia, including Tangerang (suburban of Jakarta), Medan, Samarinda, and Makassar. Therefore, the survey was conducted only in urban areas. ${ }^{1}$

Although the scope of the study is not large enough to capture national representative samples, these four cities represent the four largest geographic islands in Indonesia - Java, Sumatera, Kalimantan, and Sulawesi - covering 33 percent of lifetime migrants and recent migrants from rural areas in Indonesia (Resosudarmo et al., 2009b). Tangerang and Samarinda are younger cities, while Medan and Makassar are older cities providing diverse migrant socioeconomic experiences (Manning and Pratomo 2013). The information on the concentration of migrants in each region was derived from the 2005 Intercensal Population Survey (Supas), which provided information on residence at time of birth for all individuals, and residence five years previously for individuals aged 6 or above.

The sampling frame in the survey follows the same list of selected census blocks or residential segments (about $12 \%$ of total blocks) used by the Central Board of Statistics for the 2007 National Socio-Economic Household Survey (Susenas) in each of the selected cities (Resosudarmo et al., 2009b). Susenas is a large-scale, cross-sectional and national representative survey to capture the socioeconomic conditions of all regions in Indonesia.

\footnotetext{
${ }^{1}$ To distinguish urban and rural areas, RUMiCI follows the Central Board of Statistics classification based on population density, number of agricultural households, and presence of some typical urban infrastructures.
} 
Based on the sampling frame, RUMiCI aims to obtain a total of 2,500 households, including migrants and nonmigrants. ${ }^{2}$

In RUMiCI, rural-urban migrants for Indonesia are defined as those who have lived at least five years continuously before 12 years old (the age before graduating from primary school). It is, therefore, expected that these migrants had childhood experiences in a rural environment. An individual who was born in the village but moved to the city after just few years or who had lived less than five years as a child in the village is therefore not defined as a migrant due to the fact that his or her skills and experiences may not be different from those of local residents. Moreover, recent migrants are defined as those who had moved to the city in the past five years, while lifetime migrants are defined as those who had moved to the city for five years or more.

The main advantage of this dataset compared to other datasets in Indonesia, such as the Indonesian Family Life Survey (IFLS) or the Population Census, is its focus on the ruralurban migration of a large number of households. In practice, the IFLS is a set of longitudinal data covering some questions about rural-urban migration but it is collected at a relatively infrequent interval, while the Population Census and Supas do not focus on changes in welfare and socioeconomic conditions of migrants and are collected at a particular point of time. The other national representative survey, such as the Indonesian National Labor Force Survey (Sakernas), does not provide data on rural-urban migration.

To determine the probability of individuals at the selected cities living below the poverty line, an ordered probit model is estimated by a maximum likelihood method. The survey data analysis is estimated to provide robust standard errors in the role of complex data design. ${ }^{3}$ In the ordered probit model, the dependent variables include three different poverty levels based on the definition constructed by the Indonesian Central Board of Statistics using household expenditure data in four cities, represented by $j$ :

$j=0$ : poor households;

$j=1$ : near-poor households;

$j=2$ : nonpoor households.

Poor households are selected if the individual is living in a poor household (household expenditure is below the poverty line), while near-poor households are selected if the individual is living between the poverty line and 20 percent above the poverty line (household expenditure is between the poverty line until $1.2 \mathrm{x}$ the poverty line). Near-poor households are examined to see the number of individuals in the vulnerable category (in between poor and nonpoor categories). In addition, nonmigrant households are added if the individual is living in a nonpoor household (household expenditure is above $1.2 \mathrm{x}$ the poverty line). The poverty line is the 2011 poverty line at selected cities based on Central Board of Statistics' calculation.

The main independent variable used in the first estimate is the migration status, namely, migrants and nonmigrants. As discussed above, migrants are defined as those who have lived in urban areas at least five years continuously before 12 years old. The other independent variables (covariates) used in the equation include (i) dummies of city of residents, (ii) gender of household head, (iii) household head's occupation, (iv) age of household head, (v) number of dependents, and (vi) educational attainment of household

\footnotetext{
${ }^{2}$ In practice, RUMiCI tries to obtain the same proportion of migrants and nonmigrants in each selected city to maximize the accuracy of estimates. However, there are some difficulties in finding the large number of recent migrant households in some cities, giving around 900 households for each nonmigrant household and lifetime migrant household, and around 600 households only for recent migrants (Resosudarmo et al., 2009b).

3 This is conducted by svyoprobit on Stata using sampling weight based on the estimated migrant population from specific district in the Population Census 2010 (IPUMS International), following a method similar to that of Resosudarmo and Suryadarma (2014).
} 
head. To examine the dynamic of the socioeconomic condition at destination, the household poverty status of individuals in 2008 (the first round of the survey) is added as one explanatory variable. The interaction between migration status (migrant or nonmigrant) and the household poverty status of individuals in 2008 are also added to see the dynamics or potential of poverty status of migrants at destination.

Using similar method in the second estimate, this study focuses on migrant household sample (migrants only) to examine the probability of migrants at the selected cities living below the poverty line. The dependent variable follows the previous estimate consisting of three outcomes of poverty levels including poor households, near-poor households, and nonpoor households. The migration status in the explanatory variable is divided into recent migrants and lifetime migrants based on their (rural-urban migrants) duration of stay in the city. Aside from the household and individual characteristics, some migration-related characteristics are added in the explanatory variables including whether migrants have previous activities in the modern sector (nonagricultural sector) in the village, their household monthly earnings before they moved to the cities, the main motive of migration, and whether the migrants have a network at destination before moving to the cities.

\section{Empirical Results}

Table 1 presents the descriptive statistics of the variables used in the ordered probit model for all individuals, while Table 2 presents the descriptive statistics of the variables used in the ordered probit model for migrants.

Table 1. Descriptive Statistics for Households' Poverty Status (All Individuals)

\begin{tabular}{|c|c|c|c|c|c|c|}
\hline & \multicolumn{2}{|c|}{ Poor } & \multicolumn{2}{|c|}{ Near Poor } & \multicolumn{2}{|c|}{ Nonpoor } \\
\hline & Mean & Std.Dev. & Mean & Std.Dev. & Mean & Std.Dev. \\
\hline Migrant & 0.395 & 0.489 & 0.427 & 0.495 & 0.564 & 0.495 \\
\hline Medan & 0.232 & 0.423 & 0.273 & 0.447 & 0.313 & 0.464 \\
\hline Makassar & 0.139 & 0.347 & 0.092 & 0.291 & 0.238 & 0.426 \\
\hline Samarinda & 0.266 & 0.443 & 0.279 & 0.449 & 0.177 & 0.382 \\
\hline Males HHH & 0.873 & 0.333 & 0.847 & 0.361 & 0.832 & 0.374 \\
\hline HHH Working in Industry & 0.114 & 0.318 & 0.148 & 0.356 & 0.138 & 0.345 \\
\hline HHH Working in Trade & 0.165 & 0.372 & 0.164 & 0.371 & 0.229 & 0.421 \\
\hline HHH Working in Services & 0.190 & 0.393 & 0.230 & 0.422 & 0.245 & 0.430 \\
\hline Age of $\mathrm{HHH}$ & 47.320 & 13.822 & 42.536 & 11.506 & 43.792 & 13.193 \\
\hline Age of HHH Squared & $2,429.515$ & $1,449.976$ & $1,940.929$ & $1,058.583$ & $2,091.716$ & $1,228.571$ \\
\hline Number of Dependents & 5.059 & 2.034 & 4.689 & 1.784 & 3.957 & 1.909 \\
\hline Education of $\mathrm{HHH}$ & 7.110 & 4.045 & 8.044 & 3.630 & 10.142 & 4.259 \\
\hline Poor_2008 & 0.582 & 0.494 & 0.377 & 0.486 & 0.167 & 0.373 \\
\hline Migrant*Poor_2008 & 0.228 & 0.420 & 0.142 & 0.350 & 0.068 & 0.252 \\
\hline
\end{tabular}

Std. Dev. = standard deviation.

Source: Authors' Calculation. 
Table 2. Descriptive Statistics for Households' Poverty Status (Migrants Only)

\begin{tabular}{|c|c|c|c|c|c|c|}
\hline & \multicolumn{2}{|c|}{ Poor } & \multicolumn{2}{|c|}{ Near Poor } & \multicolumn{2}{|c|}{ Nonpoor } \\
\hline & Mean & Std. Dev. & Mean & Std. Dev. & Mean & Std. Dev. \\
\hline Recent Migrants & 0.115 & 0.321 & 0.166 & 0.374 & 0.237 & 0.425 \\
\hline Medan & 0.240 & 0.429 & 0.265 & 0.444 & 0.282 & 0.450 \\
\hline Makassar & 0.135 & 0.344 & 0.120 & 0.328 & 0.244 & 0.430 \\
\hline Samarinda & 0.333 & 0.474 & 0.313 & 0.467 & 0.172 & 0.377 \\
\hline Males HHH & 0.896 & 0.307 & 0.855 & 0.354 & 0.813 & 0.390 \\
\hline HHH Working in Industry & 0.104 & 0.307 & 0.181 & 0.387 & 0.165 & 0.371 \\
\hline HHH Working in Trade & 0.167 & 0.375 & 0.241 & 0.430 & 0.223 & 0.417 \\
\hline HHH Working in Services & 0.135 & 0.344 & 0.133 & 0.341 & 0.229 & 0.421 \\
\hline Education of $\mathrm{HHH}$ & 8.365 & 3.756 & 7.940 & 3.559 & 10.471 & 4.044 \\
\hline Number of Dependent & 1.573 & 1.254 & 1.410 & 1.137 & 0.776 & 0.877 \\
\hline Previous work: Agriculture & 0.302 & 0.462 & 0.422 & 0.497 & 0.222 & 0.416 \\
\hline Earnings in the Village & 13.152 & 0.644 & 13.201 & 0.762 & 13.279 & 0.867 \\
\hline Poor-2008 & 0.577 & 0.496 & 0.305 & 0.463 & 0.129 & 0.336 \\
\hline Age of $\mathrm{HHH}$ & 46.836 & 13.554 & 43.811 & 13.078 & 42.921 & 13.737 \\
\hline Age of HHH Squared & $2,375.606$ & $1,432.89$ & $2,088.567$ & $1,256.59$ & $2,030.819$ & $1,262.45$ \\
\hline Medan & 0.230 & 0.423 & 0.244 & 0.432 & 0.268 & 0.443 \\
\hline Samarinda & 0.308 & 0.463 & 0.289 & 0.456 & 0.181 & 0.385 \\
\hline Makassar & 0.125 & 0.332 & 0.111 & 0.316 & 0.226 & 0.418 \\
\hline
\end{tabular}

Std. Dev. = standard deviation.

Source: Authors' Calculation.

In order to interpret the ordered probit analysis, this study reports the marginal effects of each coefficient because the interpretation of the raw regression is not directly informative and is not comparable within different categories. On the equations used in this study, the marginal effects provide information on the change in probabilities of each selected poverty status. Therefore, and specifically, a change in the independent variable may increase the probability of one selected poverty status category and may decrease the probability of the other selected poverty status categories, providing a zero value of total probabilities across all selected categories.

Table 3 presents the findings of the poverty status of migrants and nonmigrants at destination using ordered probit estimate. As shown in Table 3, rural-urban migrant households are less likely to be categorized as poor households (and near-poor households). In other words, they are more likely to be categorized as nonpoor in the cities. This is consistent with Resosudarmo et al. (2009a) suggesting that rural-urban migrants in Indonesia are less likely to be poor than nonmigrants since the average income of migrant households is significantly higher than that of local residents. This is possible as the migrants tend to have better socioeconomic status than the local residents. Migrants may also not belong to the poorest households at the origin due to the fact that most poor people at the origin do not migrate, lowering risk of poverty at destination. 
Table 3. Poverty Status of Migrants and Non Migrants

\begin{tabular}{lcccccc}
\hline & \multicolumn{2}{c}{ Poor } & \multicolumn{2}{c}{ Near Poor } & \multicolumn{2}{c}{ Nonpoor } \\
\cline { 2 - 7 } & M.E. & P value & M.E. & P value & M.E. & P value \\
\hline Migrant & -0.052 & 0.022 & -0.035 & 0.046 & 0.087 & 0.028 \\
\hline Males HH Head & -0.052 & 0.144 & -0.027 & 0.099 & 0.078 & 0.126 \\
\hline HHH Working in Industry & 0.029 & 0.292 & -0.019 & 0.327 & 0.048 & 0.304 \\
\hline HHH Working in Trade & -0.054 & 0.009 & -0.035 & 0.023 & 0.089 & 0.012 \\
\hline HHH Working in Services & -0.049 & 0.031 & -0.031 & 0.047 & 0.081 & 0.034 \\
\hline Age of HHH & -0.006 & 0.241 & -0.003 & 0.235 & 0.01 & 0.236 \\
\hline Age of HHH Squared & 0.00005 & 0.325 & 0.00003 & 0.319 & -0.00008 & 0.322 \\
\hline Number of Dependent & 0.022 & 0.000 & 0.013 & 0.001 & -0.035 & 0.000 \\
\hline Education of HHH & -0.013 & 0.000 & -0.008 & 0.000 & 0.021 & 0.000 \\
\hline Poor-2008 & 0.104 & 0.001 & 0.052 & 0.000 & -0.156 & 0.000 \\
\hline Migrant*Poor-2008 & 0.228 & 0.067 & 0.071 & 0.000 & -0.029 & 0.031 \\
\hline Medan & -0.054 & 0.038 & -0.033 & 0.054 & 0.087 & 0.041 \\
\hline Samarinda & 0.038 & 0.248 & 0.021 & 0.210 & -0.059 & 0.233 \\
\hline Makassar & -0.091 & 0.000 & -0.063 & 0.001 & 0.154 & 0.000 \\
\hline No of observation & 1889 & & & & & \\
\hline
\end{tabular}

Note: M.E is marginal effect, estimated by svyprobit.

Source: Authors' Calculation.

The other possible reason is that migrants who move to the cities mostly have lower dependency ratio as indicated by Effendi et al. (2009), reducing the possibility of their being categorized as poor based on per capita expenditure data of the household. The issue of dependency ratio is also supported by the number of dependents in family, a variable which significantly influences the poverty status. As shown in Table 3, the number of dependents in a family is positive for poor and near-poor categories, suggesting that a higher number of dependent increases the probability of migrants and nonmigrants to be categorized as poor and near-poor households since their cost of living is higher. This is also consistent with the study of Park and Wang (2010), which found that migrants living with more dependents will be increasing the likelihood of their poverty as measured by their per capita household expenditure.

In general, the adaptation and assimilation issues do not seem to be severe problems in rural-urban migration in Indonesia. This is supported by Effendi et al. (2009) showing that some cities, such as Medan, have pluralistic population composition by ethnicity without any fundamental barriers. The result is different with Lelkes (2007) in the case of international migration, showing that migrants tend to have higher risk of poverty at destination as they face more problems of adapting to the new environment because of their different social and cultural backgrounds, including the language barrier.

Looking at the other explanatory variables, migrants and nonmigrants with household heads working in trade and services sectors are less likely to be categorized as poor and nearpoor. In contrast, migrants and nonmigrants with household heads working in industrial sectors are not significant in number. The education of the household head is another key for migrants and nonmigrants to escape from poverty, as indicated by the negative coefficients for poor and near-poor categories. Meanwhile, the gender and age of the household heads are not significant factors in determining escape from poverty.

Another important issue is the poverty dynamic of the migrants and nonmigrants as measured by the change in poverty status from the first round of the survey (2008) to the latest survey (2011). As presented in Table 3, respondents categorized as poor in the 2008 survey tended to remain categorized as poor and near-poor in the 2011 survey. In practice, the 
coefficient of the near poor (0.052) is lower than the coefficient of the poor $(0.104)$, suggesting that migrants and nonmigrants who are poor in 2008 are finding it difficult to move from poor category into near-poor category. Similarly, among migrants, the interaction coefficient of migration status and poverty status in 2008 shows that the coefficient of poor (0.228) is relatively higher than the coefficient of near-poor (0.071) suggesting that several migrants remain trapped at the poor households level as shown in the latest round of the survey.

Table 4 presents the estimate of the poverty status among migrants only using the same method as the first estimate. Unlike the first estimate, the migration status variable used in the previous estimate is modified using recent migrants and lifetime migrants to measure the number of years migrants stayed in the cities. The results in Table 4 confirm that the probability of being poor is not significantly different between recent migrants and lifetime migrants. However, the recent migrants are more likely to be categorized as near poor, suggesting that they are more vulnerable than the lifetime migrants. The recent migrants are also less likely to be categorized as nonpoor compared to lifetime migrants, although it is only significant at 10 percent level.

Table 4. Poverty Status among Migrants (Migrants Only)

\begin{tabular}{lcccccc}
\hline & \multicolumn{2}{c}{ Poor } & \multicolumn{2}{c}{ Near Poor } & \multicolumn{2}{c}{ Nonpoor } \\
\cline { 2 - 7 } & M.E. & P value & M.E. & P value & M.E. & P value \\
\hline Recent Migrant & 0.157 & 0.166 & 0.077 & 0.052 & -0.234 & 0.100 \\
\hline Males HHH & 0.045 & 0.090 & 0.038 & 0.101 & -0.084 & 0.068 \\
\hline HHH Working in Industry & -0.045 & 0.221 & -0.038 & 0.275 & 0.083 & 0.227 \\
\hline HHH Working in Trade & -0.034 & 0.298 & -0.027 & 0.252 & 0.061 & 0.263 \\
\hline HHH Working in Services & -0.094 & 0.002 & -0.081 & 0.006 & 0.176 & 0.000 \\
\hline Education of HHH & 0.001 & 0.705 & 0.001 & 0.697 & -0.003 & 0.700 \\
\hline Previous work: Agriculture & 0.103 & 0.044 & 0.059 & 0.137 & -0.163 & 0.061 \\
\hline Number of Dependent & 0.032 & 0.012 & 0.023 & 0.074 & -0.055 & 0.015 \\
\hline Earnings in the Village & 0.009 & 0.597 & 0.006 & 0.636 & -0.015 & 0.612 \\
\hline Poor-2008 & 0.242 & 0.010 & 0.108 & 0.008 & -0.351 & 0.001 \\
\hline Age of HHH & 0.003 & 0.741 & 0.002 & 0.742 & -0.006 & 0.740 \\
\hline Age of HHH Squared & -0.000008 & 0.930 & -0.000006 & 0.930 & -0.00002 & 0.930 \\
\hline Medan & -0.065 & 0.041 & -0.053 & 0.025 & 0.119 & 0.013 \\
\hline Samarinda & -0.083 & 0.008 & -0.071 & 0.012 & 0.154 & 0.001 \\
\hline Makassar & -0.061 & 0.010 & -0.056 & 0.016 & 0.117 & 0.002 \\
\hline No observation & 844 & & & & & \\
\hline No $:$ ME
\end{tabular}

Note: M.E is marginal effect, estimated by svyprobit.

Source: Authors' Calculations.

The result confirms that the duration of migration matters. The probability of escaping from poverty increases with the duration of migration in line with the improvement in socioeconomic condition. However, as noted earlier, the probability of being categorized as poor is not significant for recent migrants. In other words, there is no significant difference in being poor between recent migrants and lifetime migrants. The possible reason is that recent migrants are more likely young migrants and are mostly single persons with lower dependency ratio, reducing the possibility of being categorized as poor based on their per capita household expenditure.

Some variables, such as previous work at origin, are important in explaining the poverty status among migrants. The probability of migrants as being poor increases if their previous work at origin is agriculture, suggesting that these migrants have no experience in 
the modern sectors. It can also be said that migrants with experience in the modern sectors at origin are less likely to be trapped in poverty. The number of dependents, once again, is important, suggesting that the higher number of dependents, the higher the risk of being categorized as poor. Migrants categorized as poor during the first survey in 2008 find difficulties in escaping from their poverty status in the latest survey in 2011 , although some migrants are better off as indicated by the positive significant effect on near-poor category. Finally, looking at destination, migrants living in Medan, Samarinda, and Makassar find less difficulties in escaping from their poverty status compared to those in Tangerang, which has a higher population density.

\section{Conclusions}

This study examines the poverty status of migrants (and nonmigrants) in four cities in Indonesia using the 2009 Rural-Urban Migration in China and Indonesia (RUMiCI) dataset. There is no clear indication so far, from the previous studies, whether migrants can move out of poverty when they stay in their cities or destination. In this study, poverty levels are divided into three categories: poor households, near-poor households, and nonpoor households, based on the definition of the Indonesian Central Bureau of Statistics's poverty lines using the expenditure approach.

Findings show that migrants tend to be categorized as nonpoor compared to nonmigrants. The lower dependency ratio in the households significantly influences the possibility of migrants to be categorized as poor households based on per capita household expenditure. Although some migrant households can escape from poverty by moving out from poor category into near-poor category, a big proportion of migrant households remains poor and cannot escape from poverty. The other important factors that help migrants to escape from poverty include the education of household heads, number of dependents, and previous work experience in the modern sector.

\section{Acknowledgement}

The author is thankful to the East Asian Development Network (EADN) Research Grant 2015 to carry out this research.

\section{References}

Adams, Jr, R. H., Page, J. (2005). Do international migration and remittances reduce poverty in developing countries? World Development, 33(10), 1645-1669.

Adams, Jr, R. H., Cuecuecha, A. (2010). The economic impact of international remittances on poverty and household consumption and investment in Indonesia. World Bank Policy Research Working Paper Series, No. WPS5433, Washington. D. C, World Bank.

Adams, Jr, R. H., Cuecuecha, A., Page, J. (2008). The impact of remittances on poverty and inequality in Ghana. World Bank Policy Research Working Paper Series, No. WPS4732, Washington. D.C, World Bank.

Effendi, T. N., Mujiyani, F. I., Darmawan, D. A., Widhyharto, D. S. (2009). Compositions and Characteristics of Rural Urban Migrants in Four Indonesian Cities. Working Paper, Centre for Population and Policy Studies, Yogyakarta, Universitas Gadjah Mada.

Firman, T., Kombaitan, B., Pradono, P. (2007). The dynamics of Indonesia's urbanisation, 1980-2006. Urban Policy and Research, 25(4), 433-454. 
Galloway, T. A., Aaberge, R. (2005). Assimilation effects on poverty among immigrants in Norway. Journal of Population Economics, 18(4), 691-718.

Gong, H., Leigh, A., Meng, X. (2012). Intergenerational income mobility in urban China. Review of Income and Wealth, 58(3), 481-503.

Lelkes, O. (2007). Poverty among migrants in Europe. European Centre for Social Welfare Policy and Research, Policy Brief. April.

Manning, C., Pratomo, D. S. (2013). Do migrants get stuck in the informal sector? Findings from a household survey in four Indonesian cities. Bulletin of Indonesian Economic Studies, 49(2), 167-192.

Meng, X., Manning, C. (2010). The great migration in China and Indonesia: Trends and institutions. The great migration: Rural-urban migration in China and Indonesia, 1-22.

Odhiambo, W., Manda, D. K. (2003). Urban poverty and labor force participation in Kenya. Paper presented at the "World Bank Urban Research Symposium," Washington D.C. on 15-17 December, 2003.

Park, A., Wang, D. (2010). Migration and urban poverty and inequality in China. China Economic Journal, 3(1), 49-67.

Resosudarmo, B. P., Suryahadi, A., Purnagunawan, R., Yumna, A., Yusrina, A. (2009a). The socioeconomic and health status of rural-urban migrants in Indonesia. Jakarta. SMERU Research Institute.

Resosudarmo, B., Yamauchi, C., Effendi, T. (2009b). Rural-urban migration in Indonesia: Survey design and implementation. Working Paper, Rumici Project, Canberra, Australian National University.

Resosudarmo, B., Suryadarma, D. (2014). The impact of childhood migration on educational attainment: Evidence from rural-urban migrants in Indonesia. Asian Population Studies, 10(3), 319-333.

Skeldon, R. (2002). Migration and poverty: Ambivalent relationships. Asia-Pacific Population Journal, 67-82.

Tacoli, C., McGranahan, G., Satterthwaite, D. (2008). Urbanization, poverty and inequity: Is rural-urban migration a poverty problem or part of the solution. The New Global Frontier: Urbanization, Poverty and Environment in the 21st century, 37-53.

Weber, B., Marre, A., Fisher, M., Gibbs, R., Cromartie, J. (2007). Education's effect on poverty: The role of migration. Applied Economic Perspectives and Policy, 29(3), 437-445.

Yang, D., Martínez, A. (2005). Remittances and poverty in migrants' home areas: Evidence from the Philippines. International Migration, Remittances, and the Brain Drain, 81-122. 